\title{
Photodegradation of Methylene Blue and Rhodamine B Using Laser-Synthesized ZnO Nanoparticles
}

\author{
Damjan Blažeka ${ }^{1}$, Julio Car ${ }^{1}$, Nikola Klobučar ${ }^{1}$, Andrea Jurov ${ }^{2,3}$, Janez Zavašnik ${ }^{2}$, \\ Andrea Jagodar ${ }^{4}$, Eva Kovačević ${ }^{4}$ (D) and Nikša Krstulović 1,*(D) \\ 1 Institute of Physics, Bijenička cesta 46, 10000 Zagreb, Croatia; dblazeka@ifs.hr (D.B.); jcar@ifs.hr (J.C.); \\ nklobucbbb@gmail.com (N.K.) \\ 2 Department of Gaseous Electronics, Jožef Stefan Institute, Jamova cesta 39, SI-1000 Ljubljana, Slovenia; \\ andrea.jurov@ijs.si (A.J.); janez.zavasnik@ijs.si (J.Z.) \\ 3 Jožef Stefan International Postgraduate School, Jamova cesta 39, SI-1000 Ljubljana, Slovenia \\ 4 GREMI, UMR7344 CNRS/Université d'Orléans, F-45067 Orléans, France; \\ andrea.jagodar@univ-orleans.fr (A.J.); eva.kovacevic@univ-orleans.fr (E.K.) \\ * Correspondence: niksak@ifs.hr; Tel.: +385-1-4698-803
}

Received: 4 September 2020; Accepted: 28 September 2020; Published: 30 September 2020

\begin{abstract}
In this paper we examined the photocatalytic efficiency of a laser-synthesized colloidal solution of $\mathrm{ZnO}$ nanoparticles synthesized by laser ablation in water. The average size of the obtained colloidal $\mathrm{ZnO}$ nanoparticles is about $47 \mathrm{~nm}$. As revealed by electron microscopy, other nanostructures were also present in the colloidal solution, especially nanosheets. A photocatalytic degradation of UV-irradiated Methylene Blue and Rhodamine B solutions of different concentration in the presence of different $\mathrm{ZnO}$ catalyst mass concentrations was studied in order to examine their influence on photodegradation rates. ZnO nanoparticles have shown high photocatalytic efficiency, which is limited due to different effects related to UV light transmittivity through the colloidal solution. Therefore, increasing catalyst concentration is effective way to increase photocatalytic efficiency up to some value where photodegradation rate saturation occurs. The photodegradation rate increases as the dye concentration decreases. These findings are important for water purification applications of laser-synthesized $\mathrm{ZnO}$ nanoparticles.
\end{abstract}

Keywords: photocatalysis; pulsed laser ablation in water; $\mathrm{ZnO}$ nanoparticles; Methylene Blue; Rhodamine B

\section{Introduction}

Water pollution is one of the greatest ecological problems which is expected to become even larger in the future and occurs due to large amount of industrial waste material released into natural waters. Photodegradation of pollutants (organic or inorganic) into simpler and non-toxic components using photocatalytic materials is a very promising and widely researched technique for wastewater treatment [1]. Zinc oxide $(\mathrm{ZnO})$ is one of the most examined and promising photocatalytic semiconductor materials after $\mathrm{TiO}_{2}$ due to its low cost, high photocatalytic efficiency and non-toxicity [2]. One of the advantages of $\mathrm{ZnO}$ over $\mathrm{TiO}_{2}$ is much larger electron mobility $\left(200-300 \mathrm{~cm}^{2} \mathrm{~V}^{-1} \mathrm{~s}^{-1}\right.$ in $\mathrm{ZnO}$ compared to $0.1-4 \mathrm{~cm}^{2} \mathrm{~V}^{-1} \mathrm{~s}^{-1}$ in $\mathrm{TiO}_{2}$ ) which contributes to larger photocatalytic efficiency in photodegradation of surrounding pollutants due to rapid electron transfer. On the other hand, the recombination rate of photogenerated electron-hole $\left(\mathrm{e}^{-} / \mathrm{h}^{+}\right)$pairs is also large, decreasing their availability for redox reactions with surrounding material and increasing energy dissipation as heat. The bandgap in $\mathrm{ZnO}(3.37 \mathrm{eV})$ is similar as in $\mathrm{TiO}_{2}(3.2 \mathrm{eV}$ in anatase) and therefore can absorb only about $5 \%$ of sunlight radiation energy [3,4]. The main disadvantage of $\mathrm{ZnO}$ is the occurrence of 
photocorrosion during light irradiation that results in a fast decrease in photocatalytic activity during irradiation and low endurance of $\mathrm{ZnO}$-based photocatalysts [5]. Photocorrosion mostly occurs due to reactions between holes and surface oxygen vacancies and the main approaches to overcome it include surface modification techniques [6]. These techniques mostly include formation of an additional layer with some of the following features: high intrinsic chemical stability, improved charge tranfer rate at the solid/liquid interface, improved $\mathrm{e}^{-} / \mathrm{h}^{+}$separation (etc due to formation of Schottky junction electric field) or high hole-conductivity (etc p-type material) [7]. The most frequently used layers in $\mathrm{ZnO}$ photocorrosion prevention are carbon-based as graphite [8], fullerene [9], graphene [10], polyaniline [11]. A large advantage of $\mathrm{ZnO}$ over $\mathrm{TiO}_{2}$ in water treatment is its high antibacterial activity towards a broad range of bacteria (especially Gram-positive) which occurs even in dark conditions due to penetration through the bacterial membrane [12]. Mechanisms which lead to photodegradation of surrounding chemicals are similar to these which occur in $\mathrm{TiO}_{2}$. The bottom of the conduction band is at $-0.5 \mathrm{~V}$ vs. the normal hydrogen electrode (NHE) which allows electron transfer to $\mathrm{O}_{2}(-0.33 \mathrm{~V}$ vs. NHE) producing very reactive superoxide $\mathrm{O}_{2}^{-}$and the top of valence band is at $+2.7 \mathrm{~V}$ vs. NHE which allows hole transfer to $\mathrm{H}_{2} \mathrm{O}\left(2.53 \mathrm{~V}\right.$ vs. NHE) producing another reactive radical $\mathrm{OH}^{*}$. These radicals are the main contributors to the degradation of chemical pollutants in water which are adsorbed at the catalyst surface and their production rate is proportional to the $\mathrm{e}^{-} / \mathrm{h}^{+}$excitation rate in the photocatalytic material which occurs due to light absorption [3,13]. Noted values of $\mathrm{ZnO}$ redox potential are the same as in $\mathrm{TiO}_{2}[14]$ ), that is the main reason for the large similarities in degradation mechanisms between these two materials. It is worth mention that both $\mathrm{ZnO}$ and $\mathrm{TiO}_{2}$ are great photocatalytic materials for $\mathrm{CO}_{2}$ gas photoreduction, especially in the presence of $\mathrm{H}_{2} \mathrm{O}$, that can lead to the formation of useful products [15]. Some of the products formed in $\mathrm{CO}_{2}$ reduction processes are methane, carbon monoxide, methanol, formic acid, ethane, ethanol and oxalate. The first step in $\mathrm{CO}_{2}$ photoreduction is adsorption of $\mathrm{CO}_{2}$ molecule at catalyst surface, and then the mechanism $\mathrm{CO}_{2}+e^{-} \rightarrow \mathrm{CO}_{2}^{-}$(where $e^{-}$ is photogenerated electron) needs to occur but due to the large potential barrier ( $-1.9 \mathrm{~V}$ vs. NHE), the reduction mechanism requires subsequent steps [16]. The large photocatalytic efficiency in degradation of carbonaceous contaminants (which occurs mainly due to $\mathrm{CO}_{2}$ adsorption) during UV-irradiation is well-established in the case of carbon-contaminated $\mathrm{TiO}_{2}$ catalysts [17].

In order to harvest a larger part of the solar irradiation spectrum, maximize the effectiveness and expand applicability of $\mathrm{ZnO}$ photocatalyst, visible-light driven photocatalysis is widely researched, with many possible solutions successfully applied. Metal doping (Ag, $\mathrm{Mn}, \mathrm{Cu}, \mathrm{Co}, \mathrm{Fe}, \mathrm{Al}$ ) can lead to the creation of intra-band levels that lead to effective bandgap narrowing, which enables absorption of light with longer wavelengths, but at the same time the photocatalytic activity is deteriorated due to the fact that the new levels act as recombination centers. This problem is less present while doping $\mathrm{ZnO}$ with non-metals $(C, N, S)$, which induces new states near the valence band [18-21]. Different types of heterogeneous nanostructures such as Janus nanoparticles [22] and plasmonic nanoparticles [23] can also show high visible-light catalytic activity. Another approach is optical light management (e.g., upconversion nanomaterials) which can be used for converting visible or NIR photons to UV photons [24].

Nanoparticles have large area/volume ratio, are great adsorbents and therefore are better for photocatalytic use than bulk materials. Nanoparticles have a large variety of applications in environmental issues [1]. ZnO nanoparticle (ZnONP) fabrication methods include sol-gel processing, vapour-liquid-solid technique, homogeneous and double-jet precipitation, hydrothermal synthesis, mechanical milling, organometallic synthesis, microwave method, spray pyrolysis, thermal evaporation, mechanochemical synthesis, [25,26] and laser synthesis which is used in this work [27]. We used pulsed laser ablation in liquid (PLAL) which is very promising method for the production of nanoparticles with high photocatalytic activity due to their high purity and is ecologically acceptable due to absence of any toxic byproducts. It also allows changing of broad range of parameters to influence nanoparticle shape, morphology and size [28-30]. More advanced laser techniques even allow laser-introduction of defects, 
bandgap and surface engineering on nanoparticles, which is a large opportunity for optimization of their photocatalytic properties [31].

In order to achieve optimization of NP colloidal solution photocatalytic activity, catalyst mass concentration is very important parameter. In this work, we measured the dependence of Methylene Blue (MB) and Rhodamine B (RB) photodegradation rates on various concentrations of laser-synthesized $\mathrm{ZnO}$ nanoparticles. $\mathrm{MB}$ or $\mathrm{RB}$ are the most frequently used dyes for measuring photodegradation rates in the presence of photocatalytic materials [32,33]. Information about photodegradation rate dependence on catalyst concentration can also help to optimize the parameters of laser ablation for the production of colloidal ZnONP (e.g., number of laser pulses). Part of this work relies on measuring photocatalytic activity dependence on initial dye concentration because from such information one can derive some assumptions about the applicability of laser-synthesized ZnONP in water pollution treatment, where average pollutant concentrations are usually much lower than the concentrations of organic dyes used in experiments.

\section{Materials and Methods}

\subsection{Syntheses of the $\mathrm{ZnO}$ Nanoparticles}

ZnONP colloidal solution was synthesized via a process of pulsed laser ablation of pure $\mathrm{ZnO}$ target (purity $>99.99 \%$, GoodFellow, Huntingdon, UK) immersed in a glass beaker containing $25 \mathrm{~mL}$ of Milliq. water. The depth of water above the $\mathrm{ZnO}$ target was $2.5 \mathrm{~cm}$. The experimental set-up is the same as we used in [27], with Nd:YAG laser (Quantel, Brilliant, Les Ulis, France) parameters as follows: number of pulses 10,000, wavelength $1064 \mathrm{~nm}$, repetition rate $5 \mathrm{~Hz}$, pulse energy $300 \mathrm{~mJ}(120 \mathrm{~mJ}$ delivered to the target), pulse duration $5 \mathrm{~ns}$, fluence $79 \mathrm{~J} / \mathrm{cm}^{2}$. Mass concentration of ablated $\mathrm{ZnO}$ material in as-synthesized colloid (in a form of nanoparticles and irregular material) was calculated from ablated crater-volume and known $\mathrm{ZnO}$ density. The crater volume was determined using an optical microscope (Leica DM2700M, Leica Microsystems, Wetzlar, Germany). As-synthesized colloidal solution is diluted in proper ratios to get solutions with $30 \%, 10 \%$ and $3 \%$ of initial ZnONP mass concentration. $\mathrm{pH}$ value of as prepared $\mathrm{ZnONP}$ colloidal solution is $7.3 \pm 0.3$. (after $30 \mathrm{~min}$ of $\mathrm{UV}$ irradiation it drops down to $6.9 \pm 0.3$ ).

\subsection{Characterization}

For structural characterization films of $\mathrm{ZnO}$ prepared by dropping of colloidal solution onto Si substrate until a visible film was formed. The shape, size and morphology of the as-synthesized $\mathrm{ZnO}$ nanoparticles or other $\mathrm{ZnO}$ structures which are present in synthesized solution were assessed by scanning electron microscope (SEM, JSM-7600F, Jeol Ltd., Tokyo, Japan), operating at $10 \mathrm{kV}$ and utilizing Everhart-Thornley low-energy secondary electron detector. The fine structures were further analyzed by dual-beam scanning-electron microscope and focused ion beam (SEM-FIB, Helios NanoLab 650, FEI B.V., Eindhoven, The Netherlands), operating at $15 \mathrm{kV}$ and additionally equipped with energy-dispersive X-ray spectrometer (X-max SDD, Oxford Instruments plc, Abingdon, UK).

$\mathrm{ZnO}$ film was structurally examined with GIXRD (grazing incidence $X$-ray diffraction) technique. The GIXRD measurements were carried out on a diffractometer equipped with a Co X-ray tube and a W/C multilayer for beam shaping and monochromatization (D5000, Siemens, Munich, Germany). The diffracted spectra were collected with a curved position sensitive detector (RADICON) in the angular range $2 \theta=33^{\circ}-88^{\circ}$. In all measurements, a fixed grazing incidence angle of $\alpha_{i}=1.5^{\circ}$ was used.

The X-ray photoelectron spectroscopy (XPS) analyses were carried out on the PHI-TFA XPS spectrometer (Physical Electronics Inc., Chanhassen, MN, USA). The analyzed area was $0.4 \mathrm{~mm}$ in diameter and the analyzed depth was about $3-5 \mathrm{~nm}$. Sample surfaces were excited by X-ray radiation from monochromatic $\mathrm{Al}$ source at photon energy of $1486.6 \mathrm{eV}$. The high-energy resolution spectra were acquired with energy analyzer operating at resolution of about $0.6 \mathrm{eV}$ and pass energy of $29 \mathrm{eV}$. During data processing the spectra from the surface were aligned by setting the $\mathrm{C} 1$ s peak at $284.8 \mathrm{eV}$, 
characteristic for $\mathrm{C}-\mathrm{C} / \mathrm{C}-\mathrm{H}$ bonds. The accuracy of binding energies was about $\pm 0.3 \mathrm{eV}$. Quantification of surface composition was performed from XPS peak intensities taking into account relative sensitivity factors provided by instrument manufacturer [34]. Two different XPS measurements were performed on each sample and average composition was calculated.

\subsection{Photocatalytic Efficiency}

A Hg UV lamp (homemade, UVA irradiation $285 \mathrm{~mW} / \mathrm{cm}^{2}$, UVB irradiation $200 \mathrm{mV} / \mathrm{cm}^{2}$, UVC $8 \mathrm{mV} / \mathrm{cm}^{2}$ ) was used for irradiation of cuvettes which contain colloidal ZnONPs and organic dye (Methylene Blue or Rhodamine B) whose photodegradation rate was measured. Photoabsorbance measurements were made before irradiation and in steps of $10 \mathrm{~min}$ of irradiation in order to analyze gradual decrease of photoabsorption curve caused by photocatalytic degradation of dye using UV-Vis spectrophotometer (Lambda 25, Perkin Elmer, Waltham, MA, USA). Initial dye concentration was varied simply by adding different volumes of dye in non-irradiated ZnONP colloidal solution. At every $\mathrm{ZnO}$ catalyst mass concentration photocatalytic degradation rate for three different initial dye concentrations was measured-which in pure Milliq water have absorbance maxima $A_{0}=2, A_{0}=1$ and $A_{0}=0.5$. MB has absorbance maximum at $\lambda=664 \mathrm{~nm}$ with corresponding extinction coefficient about $75,000 \mathrm{~cm}^{-1} / \mathrm{M}$ and $\mathrm{RB}$ has absorbance maximum at $\lambda=553 \mathrm{~nm}$ with corresponding extinction coefficient about $100,000 \mathrm{~cm}^{-1} / \mathrm{M}$. Initial dye concentrations, calculated using Beer-Lambert law, were about $2.7 \times 10^{-5} \mathrm{~mol} / \mathrm{L}$ for $\mathrm{MB}$, and about $2 \times 10^{-5} \mathrm{~mol} / \mathrm{L}$ for RB, both for $A_{0}=2$.

\section{Results and Discussion}

\subsection{Characterization of $\mathrm{ZnO}$ Colloidal Solution}

\subsubsection{ZnO Concentration}

The mass concentration of $\mathrm{ZnO}$ in as-synthesized colloidal solution is calculated according to a procedure described in [30]. Volume of a crater $V_{Z n O}$ remaining on the $\mathrm{ZnO}$ target after ablation (or volume of ablated material) was determined from crater semi-profile shown in Figure 1. with a procedure described in [35]. In short, the crater has a Gaussian shape profile and it was determined by using an optical microscope taking images at different focal positions with respect to the target surface. From such images crater radii at certain depths were determined (whose values are shown in Figure 1).

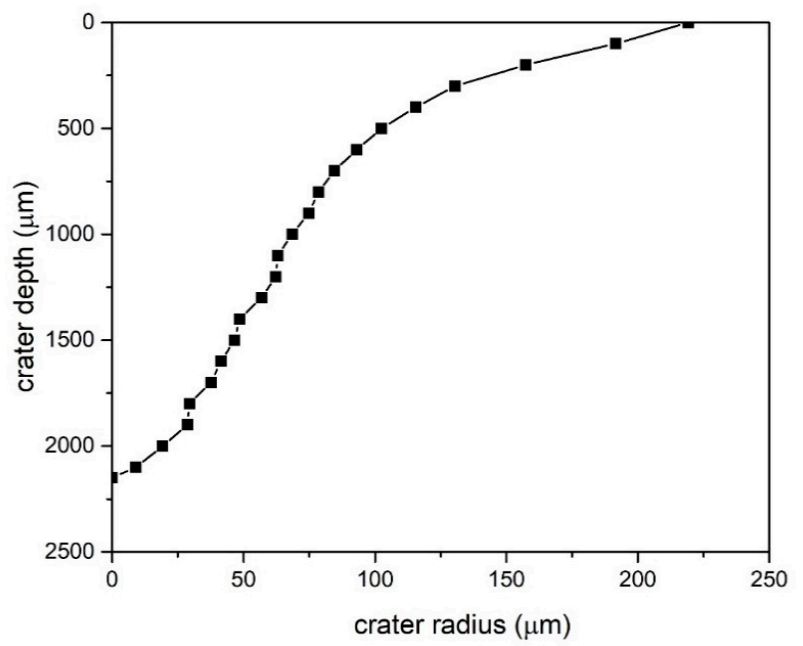

Figure 1. Semi-profile of a crater left after ablation in $\mathrm{ZnO}$ target ( $x-y$ axes are not to scale).

Total crater volume $V_{Z n O}$ is obtained as a sum of frustums formed by consecutive radii at corresponding depths. Crater volume $V_{Z n O}$ is $5.61 \times 10^{7} \mu \mathrm{m}^{3}$, which multiplied with $\mathrm{ZnO}$ density $\rho_{\mathrm{ZnO}}\left(5.61 \mathrm{~g} / \mathrm{cm}^{3}\right)$ gives the total mass $m_{\mathrm{ZnO}}$ of $\mathrm{ZnO}$ in as-synthesized colloidal solution. Finally, $\mathrm{ZnO}$ 
mass concentration $C_{100 \%}$ in as-synthesized $\mathrm{ZnO}$ solution is calculated by dividing $m_{\mathrm{ZnO}}$ with volume of Milliq water $V_{\text {liq }}$ in vessel where target was immersed and laser-irradiated:

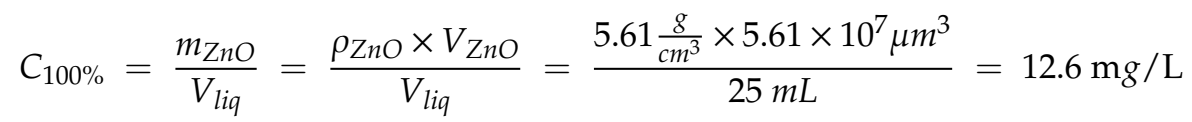

$\mathrm{ZnO}$ as-prepared solution is further diluted with Milliq water to get diluted $\mathrm{ZnO}$ colloidal solutions $\left(C_{30 \%}, C_{10 \%}, C_{3 \%}\right)$ to study dependence of photocatalytic degradation of $\mathrm{MB}$ and $\mathrm{RB}$ on different $\mathrm{ZnO}$ colloidal mass concentrations (including the pure dye cases).

\subsubsection{SEM Microscopy Observations}

Secondary electron (SE) SEM micrographs are shown in Figure 2. In Figure 2a it can be seen that, beside well-defined nanoparticles, different irregular structures are formed during ablation. The largest part of analyzed sample area looks like that shown in Figure $2 b$, with prevailing spherical nanoparticles as dominant nanostructures. From SEM images a size-distribution of nanoparticles is determined and shown in Figure 3. Size-distribution can be fitted as log-normal with distribution maximum at diameter $d=47 \pm 2 \mathrm{~nm}$. Formation of certain amount of irregular structures upon laser synthesis of ZnONP make us unavailable to calculate precisely number concentrations of ZnONP but only mass concentration of all formed structures (equals to a mass of ablated materials). Further in text we refer to $\mathrm{ZnONP}$ but taking into account that also other structures participate in photodegradation reactions at certain level which we cannot distinguish.
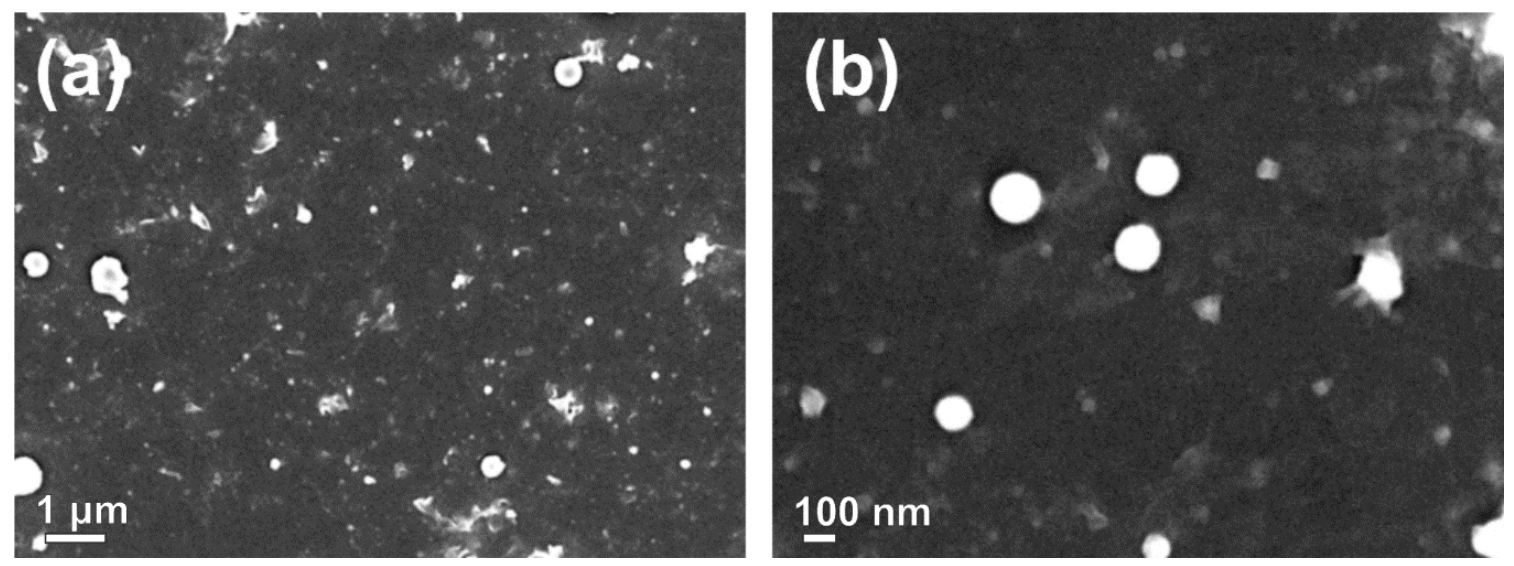

Figure 2. SE-SEM micrographs, (a) overview of synthesized nanoparticles and nanostructures and (b) detailed view of spherical $\mathrm{ZnO}$ nanoparticles.

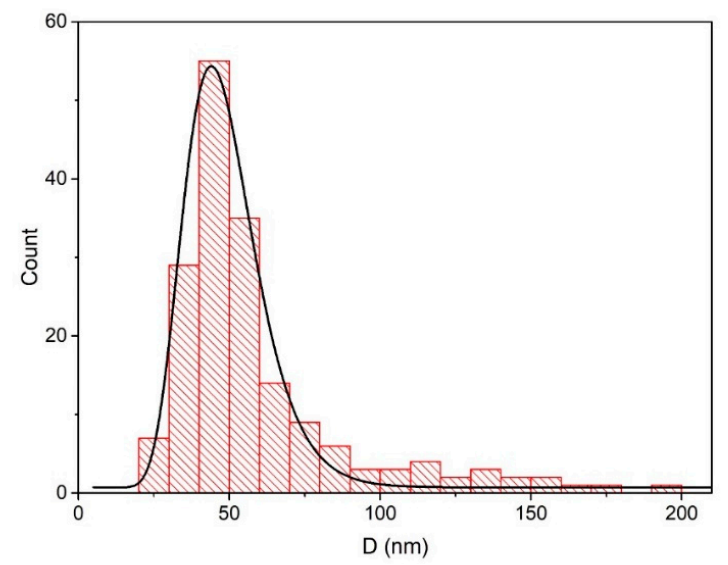

Figure 3. Size distribution of $\mathrm{ZnO}$ nanoparticles. 
Energy-dispersive X-ray spectroscopy (EDS) analysis revealed that ratio between zinc and oxygen atoms number is $52: 48$ as it can be seen from Figure S1. It points out that $\mathrm{ZnO}$ is dominant material formed in laser ablation while no significant impurities or other elements were found by this technique.

A detailed SE-SEM observation of surface morphology of ablated $\mathrm{ZnO}$ spherical nanostructures (Figure 4a) revealed structured surface. In Figure $4 \mathrm{~b}$ large nanosheets can be seen, which contain many spherical nanoparticles trapped or adhered on their surface.
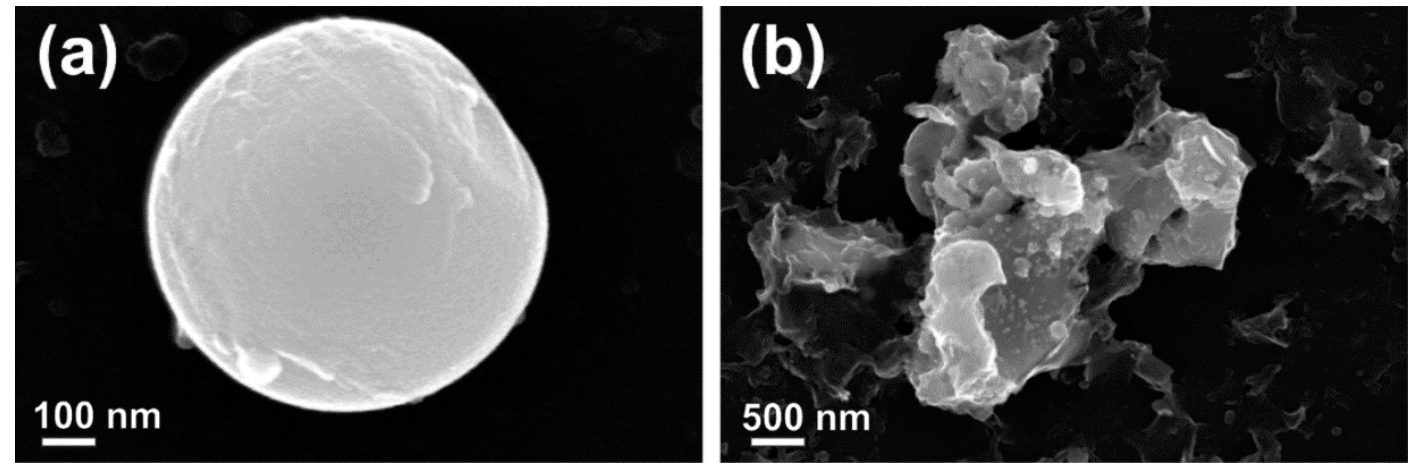

Figure 4. SE-SEM micrographs of (a) individual spherical $\mathrm{ZnO}$ nanoparticles showing structured morphology; and (b) large nano-sheets, covered by nano-sized particles.

\subsubsection{XRD and XPS Analyses}

The crystallinity of ZnONPs was examined by GIXRD measurements. The GIXRD spectrum, together with the reference patterns for the ZnO phase (JCPDS-ICDD card \#36-1451), is shown in Figure 5 and it reveals that ZnONP are crystalline. Experimental GIXRD spectra show only the peaks characteristic for the hexagonal wurtzite phase of $\mathrm{ZnO}$ crystallites. In addition, the presence of all main $\mathrm{ZnO}$ diffraction peaks in the experimental curves indicate randomly oriented crystallites within the film (no preferential orientation).

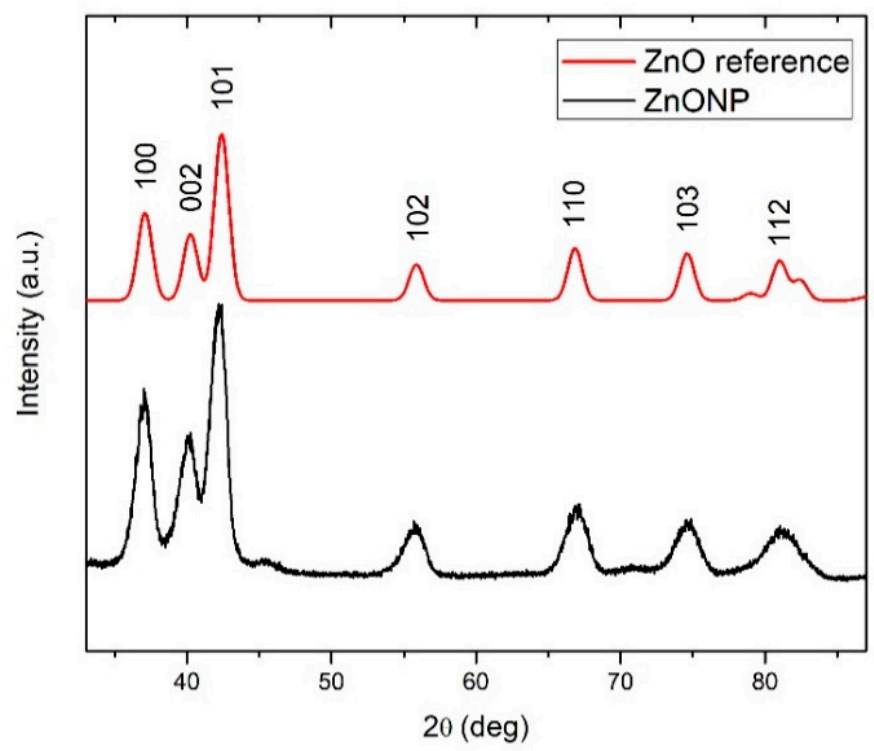

Figure 5. XRD pattern of $\mathrm{ZnO}$.

High energy resolution spectra $\mathrm{Zn} 2 \mathrm{p}_{3 / 2}$ and $\mathrm{O} 1 \mathrm{~s}$ are shown in Figure 6a,b, respectively. Zn $2 \mathrm{p}_{3 / 2}$ peak was fitted with one component peak at $1021.5 \mathrm{eV}$ which corresponds to $\mathrm{Zn}^{2+}$ states in the $\mathrm{ZnO}$ lattice. The $\mathrm{O} 1 \mathrm{~s}$ spectrum was fitted with two components. The peak at $531.6 \mathrm{eV}$ (87\% of relative intensity) may be assigned partially to chemisorbed $\mathrm{OH}$ or $\mathrm{C}-\mathrm{O}$ groups and partially to oxygen 
deficient regions within the matrix of $\mathrm{ZnO}$ and therefore with concentration of oxygen vacancies [36]. $\mathrm{OH}$ or $\mathrm{C}-\mathrm{O}$ groups probably originating from surface contamination during sample preparation under atmospheric conditions as it can be concluded from XPS depth profiles shown in Figure S2 (C and O features are only present at sample surface). The contamination was also observed form XPS survey spectrum shown in Figure S3. Peak at $530.3 \mathrm{eV}$ (13\% of relative intensity) was assigned to $\mathrm{O}^{2-}$ oxide structure in $\mathrm{ZnO}$ lattice.

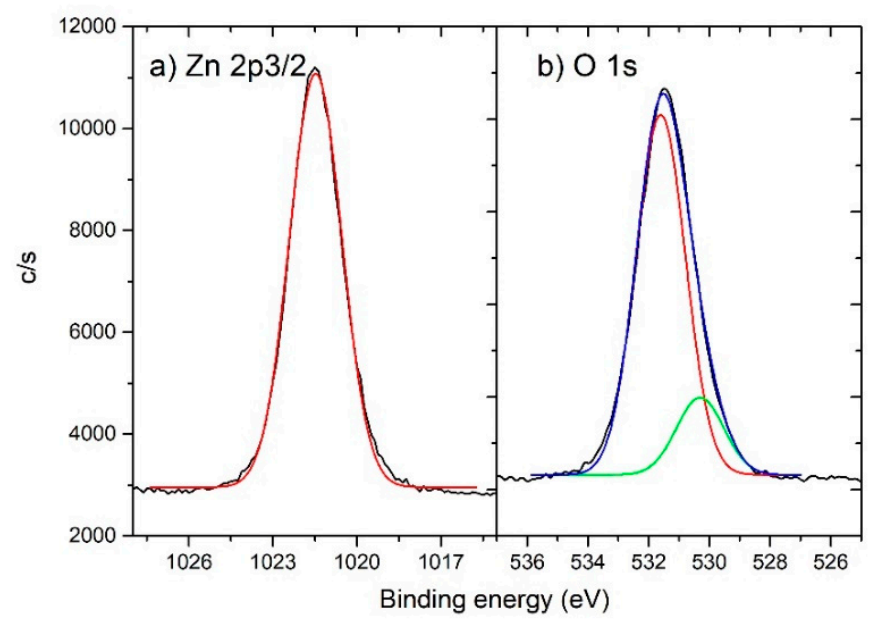

Figure 6. High resolution XPS spectra of $\mathrm{ZnO}$ with fit spectra for (a) $\mathrm{Zn} 2 \mathrm{p}_{3 / 2}$ and (b) O 1s.

\subsubsection{Bandgap Determination}

In order to calculate bandgap of as-synthesized colloidal ZnONP a Tauc plot was made from UV-Vis data as shown in Figure 7. A Tauc plot for was used direct bandgap calculation $\left((A h f)^{2} v s . h f\right)$ because $\mathrm{ZnO}$ is known as direct-bandgap semiconductor (shown in the inset in Figure 7). The direct-bandgap from the Tauc plot is $3.30 \mathrm{eV}$, which is very close to well-known value of the $\mathrm{ZnO}$ bandgap ( $3.37 \mathrm{eV}$ ). Larger bandgap deviations would point to changes and deformations in the optical and crystal properties in the $\mathrm{ZnO}$ material that could have a high impact on the physical and photocatalytic properties of colloidal solutions.

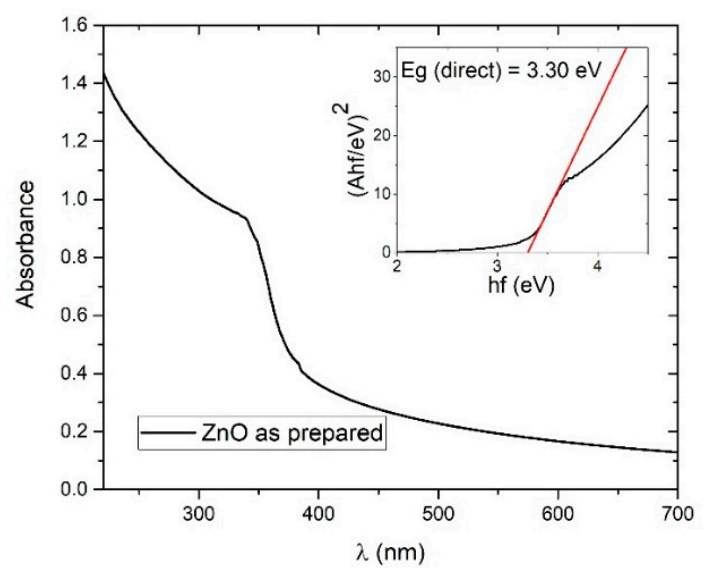

Figure 7. Photoabsorption spectrum of $\mathrm{ZnO}$ colloidal solution; Inset: Tauc plot for direct bandgap calculation.

\subsection{Photodegradation Rate Calculation}

In Figure 8 an example of the decrease of absorbance of irradiated solution during photodegradation of (a) MB and (b) RB dyes is shown. These examples are made with solutions which have as-synthesized 
concentration of $\mathrm{ZnO}$ (mass concentration $C_{100 \%}$ ) and initial amount of dye which corresponds to dye photoabsorbance maximum $A_{0}=2$ (in an equivalent amount of pure water).
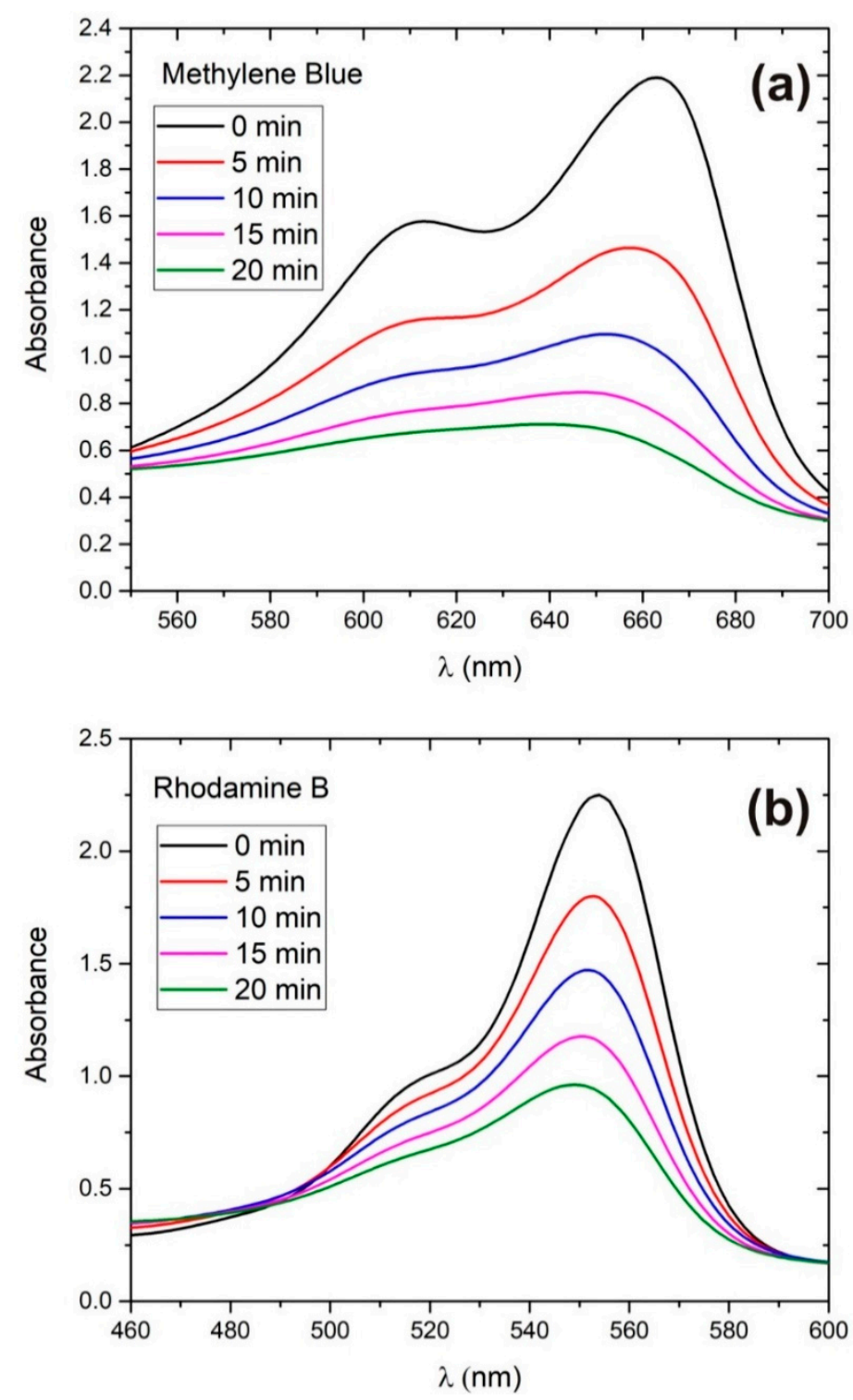

Figure 8. Photocatalytic degradation of (a) MB and (b) RB in as-prepared ZnO solution.

Figure S4 shows the time-dependence of photoabsorbance maximum of UV-irradiated colloidal solution which contains (a) $\mathrm{MB}$ and (b) $\mathrm{RB}$ and four different amounts of $\mathrm{ZnO}$ catalyst mass concentrations in case of initial dye concentration corresponding to $A_{0}=2$.

Photocatalytic degradation rates were calculated using pseudo-first order reaction rate model, described in $[37,38]$, using the formula:

$$
\mathrm{d} C / \mathrm{d} t=-D R \times C
$$

where $C$ is the concentration of dye while $D R$ is the rate constant or simply the degradation rate of the photocatalytic reaction. The solution of Equation (2) is given by:

$$
C(t)=C_{0} e^{-D R \times t}
$$

where $C_{0}$ is initial dye concentration and $\mathrm{t}$ is irradiation time. 
From the Beer-Lambert law $A=\sigma \cdot C \cdot l$ one can conclude that the dye time-dependent photoabsorbance peak $\mathrm{A}$ is proportional to the concentration of dye $C$, because the cross-section $\sigma$ and absorption path-length $l$ do not change during photodegradation. One can simply take $C / C_{0}=A / A_{0}$. That is the reason one can use Equation (3) and photoabsorption measurements for determination of degradation rates. In Figure 9 plots of $\ln \left(C / C_{0}\right)$ vs. $t$ for (a) $M B$ and (b) RB are shown as an example for the $A_{0}=2$ case. From linear regression of $\ln \left(C / C_{0}\right)$ vs. $t$ a photodegradation rates $D R$ and $D R$ errors were evaluated.
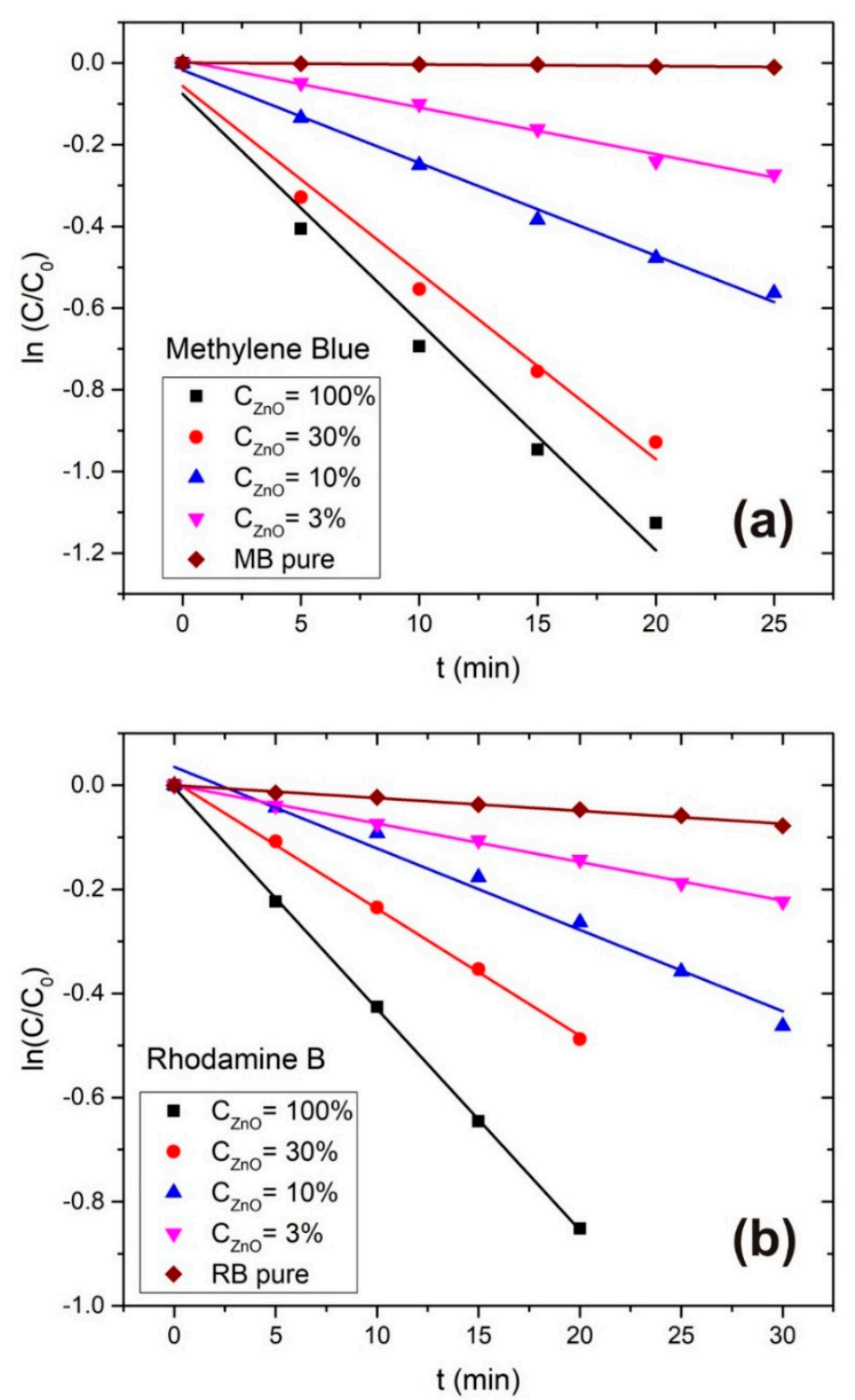

Figure 9. $\ln \left(C / C_{0}\right)$ vs. $t$ plot for (a) MB and (b) RB at different ZnONP concentrations.

Photodegradation half-time $t_{1 / 2}$ (time after the dye concentration drops to a half of its initial value) is also determined for the related reactions. In Table 1 the corresponding photodegradation rates, photodegradation half-times and $R^{2}$ from fit are summarized for $\mathrm{MB}$ and $\mathrm{RB}$. 
Table 1. Photodegradation rates, $R^{2}$ and photodegradation half-time derived from pseudo-first order rate model for $\mathrm{MB}$ and $\mathrm{RB}$ for different concentrations of $\mathrm{ZnONP}$ and for different dye concentrations.

\begin{tabular}{|c|c|c|c|c|c|c|c|}
\hline \multirow{2}{*}{$A_{0}$} & \multirow{2}{*}{$c_{\mathrm{ZnO}}$} & \multicolumn{3}{|c|}{ MB } & \multicolumn{3}{|c|}{ RB } \\
\hline & & $D R\left(\min ^{-1}\right)$ & $R^{2}$ & $t_{1 / 2}(\min )$ & $D R\left(\min ^{-1}\right)$ & $R^{2}$ & $t_{1 / 2}(\min )$ \\
\hline \multirow{5}{*}{2} & $C_{100 \%}$ & 0.0559 & 0.9784 & 12.4 & 0.0425 & 0.9998 & 16.3 \\
\hline & $C_{30 \%}$ & 0.0457 & 0.9838 & 15.2 & 0.0244 & 0.9988 & 28.4 \\
\hline & $C_{10 \%}$ & 0.0227 & 0.9934 & 30.5 & 0.0156 & 0.9793 & 44.3 \\
\hline & $C_{3 \%}$ & 0.0114 & 0.9916 & 60.8 & 0.0074 & 0.9983 & 93.5 \\
\hline & pure dye & 0.0004 & 0.9350 & 1733 & 0.0025 & 0.9899 & 281 \\
\hline \multirow{5}{*}{1} & $C_{100 \%}$ & 0.0805 & 0.9855 & 8.6 & 0.0510 & 0.9855 & 13.6 \\
\hline & $C_{30 \%}$ & 0.0636 & 0.9914 & 10.9 & 0.0301 & 0.9914 & 23.1 \\
\hline & $C_{10 \%}$ & 0.0565 & 0.9991 & 12.3 & 0.0258 & 0.9991 & 26.9 \\
\hline & $C_{3 \%}$ & 0.0192 & 0.9872 & 36.1 & 0.0168 & 0.9872 & 41.4 \\
\hline & pure dye & 0.0010 & 0.9844 & 673 & 0.0036 & 0.9863 & 193 \\
\hline \multirow{5}{*}{0.5} & $C_{100 \%}$ & 0.0983 & 0.9942 & 7.1 & 0.0538 & 0.9979 & 12.9 \\
\hline & $C_{30 \%}$ & 0.0820 & 0.9925 & 8.5 & 0.0343 & 0.9942 & 20.2 \\
\hline & $\mathrm{C}_{10 \%}$ & 0.0456 & 0.9964 & 15.2 & 0.0262 & 0.9914 & 26.4 \\
\hline & $C_{3 \%}$ & 0.0185 & 0.9709 & 37.5 & 0.0258 & 0.9927 & 26.9 \\
\hline & pure dye & 0.0026 & 0.9688 & 266 & 0.0044 & 0.9800 & 159 \\
\hline
\end{tabular}

The dependence of photodegradation rates on ZnONP catalyst mass concentration (including the pure dye cases) is shown in Figure 10 for (a) MB and (b) RB for all three initial dye concentrations $\left(A_{0}=2,1\right.$ and 0.5). $D R$ errors are also shown for each $D R$ value.

The MB photodegradation rate, shown in Figure 10a, grows while $C_{\mathrm{ZnO}}$ increases over the full measured range, but the slope of $D R$ vs. $C_{\mathrm{ZnO}}$ curve decreases in the same range. Such a result can be explained in terms of the interplay between two effects. The first effect contributes to photodegradation rate growth when the amount of photocatalytic material increases and hence the area of the catalyst surface. It means that the number of active sites available for $\mathrm{e}^{-} / \mathrm{h}^{+}$excitation and redox reactions is larger, so the production rate of reactive radicals responsible for photodegradation of dye increases. The second effect contributes to the photodegradation rate decrease due to decreasing of UV light transmittivity in the colloidal solution with increasing $\mathrm{ZnO}$ concentration. This means that $\mathrm{e}^{-} / \mathrm{h}^{+}$ excitation caused by UV light irradiating photocatalytic material will also decrease, especially in levels of solution which are at larger distance from the light incidence surface of the cuvette.

According to this analysis, it is expected that there exists some catalyst concentration $C_{M}$ where the photodegradation rate achieves a maximal value due to interplay of the above- mentioned effects. The existence of such optimal concentration $C_{M}$ can be seen in [39] while measuring $\mathrm{MB}$ photodegradation in the presence of different concentrations of $\mathrm{TiO}_{2}$ nanoparticles, in [40] when varying the $\mathrm{ZnO}$ and $\mathrm{TiO}_{2}$ catalyst load for photocatalytic degradation of Acid-brown 14, and in [41] when varying the $\mathrm{ZrO}_{2}$ catalyst concentration for photocatalytic degradation of Methylene Blue and Rhodamine B.

Catalyst concentrations examined in this work are obviously lower than $C_{\mathrm{M}}$, although saturation of $\mathrm{MB}$ photodegradation rate is obtained when increasing $C_{\mathrm{ZnO}}$. In our case, the highest photodegradation rate of $\mathrm{MB}$ was achieved when $A_{0}=0.5$ and $C_{\mathrm{ZnO}}=100 \%$ where $D R=0.0983 \mathrm{~min}^{-1}$ and $t_{1 / 2}=7.1 \mathrm{~min}$. It is interesting to compare this photocatalytic efficiency with the one obtained using $\mathrm{ZnO}$ nanoparticles synthesized by other methods, for example sol-gel or precipitation. These methods were used for synthesis of $\mathrm{ZnO}$ nanoparticles in [42] where photodegradation of UV-irradiated MB in their presence was measured for different catalyst mass concentrations. Here, the optimal catalyst load was determined to be $250 \mathrm{mg} / \mathrm{L}$, and corresponding photodegradation rates were $0.008 \mathrm{~min}^{-1}$ for $\mathrm{ZnONP}$ synthesized by sol-gel, and $0.0079 \mathrm{~min}^{-1}$ for ZnONP synthesized by percipitation method, both at initial MB concentration $20 \mathrm{mg} / \mathrm{L}$. The degradation rates which we obtained are more than 10 times larger at about 20 times lower concentration of $\mathrm{ZnO}$ catalyst, which points to the great photocatalytic efficiency of the laser-synthesized $\mathrm{ZnO}$ nanoparticles in our work. 

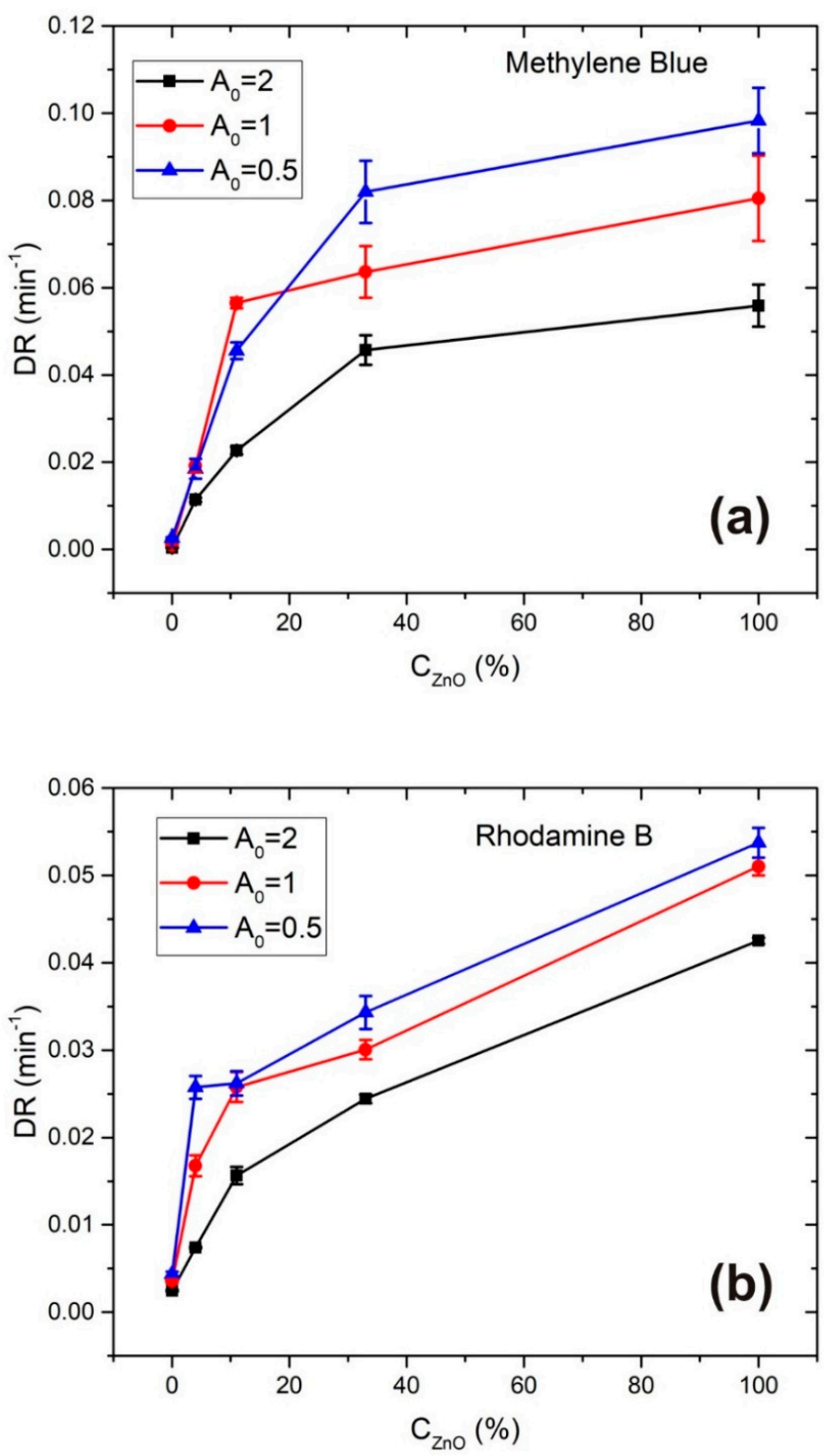

Figure 10. Photodegradation rates of (a) MB and (b) RB vs. ZnONP catalyst mass concentration for different initial dye concentrations.

Photodegradation rate of RB shown in Figure $10 \mathrm{~b}$ increases with $\mathrm{ZnO}$ concentration at all three applied dye concentrations, but the saturation is much less emphasized than in the MB case. It means that, in this case, the first effect mentioned above in the MB degradation analysis, related to changing of the active surface area of photocatalytic material, contributes much more than the second effect, related to the changing transmittivity of UV light. The reason for such a difference, when compared to the MB case, can be attributed to the much lower UV absorbance of the RB dye itself as it can be seen in Figure S5. Therefore, a UV light intensity which is sufficient for significant photocatalytic activation is present at deeper solution distances measured from the light-incidence side of the cuvette when compared to $\mathrm{MB}$ at the same $\mathrm{ZnO}$ concentration value. Higher values of $D R$ error in $\mathrm{MB}$ degradation compared to $\mathrm{RB}$ could be attributed to the fact that during $\mathrm{MB}$ photodegradation much larger changes in UV transmittivity of the irradiated solution occur than in the RB case, that leads to more significant $D R$ change during degradation time. Here, the highest photodegradation rate of RB was achieved when $A_{0}=0.5$ and $C_{\mathrm{ZnO}}=100 \%$ where $D R=0.0537 \mathrm{~min}^{-1}$ and $t_{1 / 2}=12.9 \mathrm{~min}$.

In the case of $\mathrm{MB}$, the difference between photodegradation rate at $\mathrm{ZnO}$ catalyst concentrations $C_{100 \%}$ and $C_{30 \%}$ is smaller than $20 \%$. This means that colloidal solutions with $\mathrm{ZnO}$ catalyst concentrations 
close to $C_{30} \% \approx m g / L$ can be used in photocatalytic degradation of $M B$ with almost the same effect, what consequently leads to a material and energy saving and minimization of possible ZnONP agglomeration.

In addition, a comparison between the photodegradation rates for $C_{100 \%}$ and $C_{30 \%}$ at different initial dye concentrations is given in Table 2. When observing the degradation rate dependence on initial dye concentration it is obvious that the photodegradation rate decreases with increasing initial dye concentration. Such a relation is also obtained in $[32,40,43]$ where the explanation for such a result is attributed to several reasons.

Table 2. Photodegradation rates of $\mathrm{MB}$ and $\mathrm{RB}$ for different initial dye concentrations and $\mathrm{ZnO}$ catalyst concentrations $C_{100 \%}$ and $C_{30 \%}$; Ratio $D R\left(A_{0}=0.5\right) / D R\left(A_{0}=2\right)$ for each case.

\begin{tabular}{ccccc}
\hline Dye Abs. Maxima & \multicolumn{2}{c}{$\boldsymbol{C}_{\mathbf{1 0 0} \%}$} & \multicolumn{2}{c}{$\boldsymbol{C}_{\mathbf{3 0} \%}$} \\
\hline$A_{0}$ & $D R(\mathrm{MB}) / \mathrm{min}^{-1}$ & $D R(\mathrm{RB}) / \mathrm{min}^{-1}$ & $D R(\mathrm{MB}) / \mathrm{min}^{-1}$ & $D R(\mathrm{RB}) / \mathrm{min}^{-1}$ \\
\hline 2 & 0.056 & 0.043 & 0.046 & 0.024 \\
1 & 0.081 & 0.051 & 0.064 & 0.030 \\
0.5 & 0.098 & 0.054 & 0.082 & 0.034 \\
\hline$D R\left(A_{0}=0.5\right) / D R\left(A_{0}=2\right)$ & 1.75 & 1.26 & 1.78 & 1.42 \\
\hline
\end{tabular}

The first one is UV-light absorption at dye molecules (both free or adsorbed at catalyst surface) and their degradation byproducts, so less light intensity is available for creation of $\mathrm{e}^{-} / \mathrm{h}^{+}$pairs in nanoparticles. This effect should be larger in MB than in RB due to the high UV absorbance of MB (note that the MB absorption features around $300 \mathrm{~nm}$ coincide with both the emission line at $300 \mathrm{~nm}$ and emission band peaking at $280 \mathrm{~nm}$ from $\mathrm{Hg}$ lamp as shown in Figure S5), and this is probably why the ratio between photodegradation rates at different $\mathrm{A}_{0}$ for the same $C_{\mathrm{ZnO}}$ is larger in the $\mathrm{MB}$ than in the RB case. That can be seen in the last row of the Table 2 where the ratio $D R\left(A_{0}=0.5\right) / D R\left(A_{0}=2\right)$ is given for $\mathrm{MB}$ and $\mathrm{RB}$ degradation in the presence of $C_{100 \%}$ and $C_{30 \%} \mathrm{ZnO}$ catalyst concentrations.

Furthermore, excessive coverage of the catalyst surface with dye molecules can significantly decrease the degradation rate because the UV-screening effect prevents production of a sufficient amount of reactive radicals needed for immediate degradation of the adsorbed species. Therefore, the effective area of the active catalyst surface is decreased so it affects the photodegradation rate in the same way as decreasing the amount of photocatalyst.

The next reason is consumption of reactive radicals due to interactions with degradation byproducts, so less of them are available for dye degradation. This effect is enhanced due to fact that dye molecules should be adsorbed at the catalyst surface in order to be photodegraded, so degradation byproducts are produced very close to the active catalyst area and have a large probability to take part in reactions with radicals.

\section{Conclusions}

Colloidal solution synthesized by pulsed laser ablation of $\mathrm{ZnO}$ target, which contains mostly $\mathrm{ZnO}$ nanoparticles, has shown strong photocatalytic properties in the degradation of Methylene Blue and Rhodamine B. The photodegradation rate is about $40 \%$ higher for Methylene Blue when compared to Rhodamine B. Within the range of catalyst and dye concentrations used in this work, photocatalytic activity is larger for larger concentrations of $\mathrm{ZnO}$ catalyst and for smaller initial dye concentration. Degradation rate growth while increasing catalyst concentration is more emphasized in Rhodamine B than in Methylene Blue. For Methylene Blue, saturation of the degradation rate is obtained in the observed catalyst concentration range. These discrepancies are in relation with propagation of UV light through the medium which is affected by the $\mathrm{ZnO}$ concentration and the UV absorbance of the dye (Methylene Blue has a much stronger UV absorption than Rhodamine B). The fact that photodegradation rate is much larger at lower dye concentrations is very promising in terms of water purification applications, where pollutant concentrations are usually much lower than those used in this paper. 
Supplementary Materials: The following are available online at http://www.mdpi.com/1996-1944/13/19/4357/s1, Figure S1: EDS measurements of ZnONP; Figure S2: XPS depth profile of the layer of ZnO on Si substrate; Figure S3: XPS survey spectrum of ZnO; Figure S4: Photoabsorbance peak dependence on irradiation time for different $\mathrm{ZnO}$ mass concentrations of (a) Methylene Blue and (b) Rhodamine B; Figure S5: Absorbance spectra of pure $\mathrm{ZnONP}$ colloid, $\mathrm{MB}$ and RB in comparison with $\mathrm{Hg}$ lamp emission spectrum.

Author Contributions: Conceptualization, D.B. and N.K. (Nikša Krstulović); methodology, D.B., N.K. (Nikola Klobučar) and N.K. (Nikša Krstulović); software, J.C.; validation, D.B. and N.K. (Nikša Krstulović); formal analysis, D.B., N.K. (Nikola Klobučar), J.C., and N.K. (Nikša Krstulović); investigation, D.B., N.K. (Nikša Krstulović), N.K. (Nikola Klobučar), A.Ja.; resources, E.K. and N.K. (Nikša Krstulović); writing-original draft preparation, D.B. and N.K. (Nikša Krstulović); writing—review and editing, D.B. and N.K. (Nikša Krstulović); visualization, A.Ju. and J.Z.; supervision, N.K (Nikša Krstulović). and E.K.; project administration, N.K (Nikša Krstulović).; funding acquisition, N.K (Nikša Krstulović). and E.K. All authors have read and agreed to the published version of the manuscript.

Funding: This research was supported by the Croatian Science Foundation under the projects IP-2019-04-6418 and PZS-2019-02-5276.

Acknowledgments: We acknowledge Krešimir Salamon for XRD and Janez Kovač for XPS analysis.

Conflicts of Interest: The authors declare no conflict of interest.

\section{References}

1. Pathakoti, K.; Manubolum, M.; MinHwang, H. Nanotechnology applications for environmental industry. In Handbook of Nanomaterials for Industrial Applications; Elsevier: Amsterdam, The Netherlands, 2018; Chapter 48; pp. 894-907.

2. Chakrabarti, S.; Dutta, B.K. Photocatalytic degradation of model textile dyes in wastewater using $\mathrm{ZnO}$ as semiconductor catalyst. J. Hazard. Mater. B 2004, 112, 269-278. [CrossRef] [PubMed]

3. Qi, K.; Cheng, B.; Yu, J.; Ho, W. Review on the improvement of the photocatalytic and antibacterial activities of ZnO. J. Alloys Compd. 2017, 727, 792-820. [CrossRef]

4. Song, L.; Wang, Y.; Ma, J.; Zhang, Q.; Shen, Z. Core/shell structured Zn/ZnO Nanoparticles Synthesized by Gaseous Laser Ablation with Enhanced Photocatalysis Efficiency. Appl. Surf. Sci. 2018, 442, 101-105. [CrossRef]

5. Hariharan, C. Photocatalytic degradation of organic contaminants in water by ZnO nanoparticles: Revisited. Appl. Catal. A Gen. 2006, 304, 55-61. [CrossRef]

6. Lee, K.M.; Lai, C.W.; Ngai, K.S.; Juan, J.C. Recent developments of zinc oxide based photocatalyst in water treatment technology: A review. Water Res. 2016, 88, 428-448. [CrossRef]

7. Bae, D.; Seger, B.; Vesborg, P.C.K.; Hansen, O.; Chorkendorff, I. Strategies for stable water splitting via protected photoelectrodes. Chem. Soc. Rev. 2017, 46, 1933-1954. [CrossRef]

8. Zhang, L.; Cheng, H.; Zong, R.; Zhu, Y. Photocorrosion Suppression of ZnO Nanoparticles via Hybridization with Graphite-like Carbon and Enhanced Photocatalytic Activity. J. Phys. Chem. C 2009, 113, 2368-2374. [CrossRef]

9. Fu, H.; Xu, T.; Zhu, S.; Zhu, Y. Photocorrosion Inhibition and Enhancement of Photocatalytic Activity for ZnO via Hybridization with C60. Environ. Sci. Technol. 2008, 42, 8064-8069. [CrossRef]

10. Tayebi, M.; Tayebi, A.; Lee, B.K. Photocorrosion suppression and photoelectrochemical (PEC) enhancement of $\mathrm{ZnO}$ via hybridization with graphene nanosheets. Appl. Surf. Sci. 2020, 502, 144-189. [CrossRef]

11. Kim, H.; Yang, B.L. A polyaniline-coated ZnS/ZnO/FTO photoelectrode for improving photocorrosion prevention and visible light absorption. New J. Chem. 2019, 43, 16699-16705. [CrossRef]

12. Barnes, R.J.; Molina, R.; Xu, J.; Dobson, P.J.; Thompson, I.P. Comparison of $\mathrm{TiO}_{2}$ and $\mathrm{ZnO}$ nanoparticles for photocatalytic degradation of methylene blue and the correlated inactivation of gram-positive and gram-negative bacteria. J. Nanopart. Res. 2013, 15, 1432. [CrossRef]

13. Ong, C.B.; Ng, L.Y.; Mohammad, A.W. A review of ZnO particles as solar photocatalysts: Synthesis, mechanisms and applications. Renew. Sust. Energy Rev. 2018, 81, 536-551. [CrossRef]

14. Ma, D.; Zhai, S.; Wang, Y.; Liu, A. Chuncheng Chen $\mathrm{TiO}_{2}$ Photocatalysis for Transfer Hydrogenation. Molecules 2019, 24, 330. [CrossRef] [PubMed]

15. Mahmodi, G.; Sharifni, S.; Madani, M.; Vatanpour, V. Photoreduction of carbon dioxide in the presence of $\mathrm{H}_{2}$, $\mathrm{H}_{2} \mathrm{O}$ and $\mathrm{CH}_{4}$ over $\mathrm{TiO}_{2}$ and $\mathrm{ZnO}$ photocatalysts. Sol. Energy 2013, 97, 186-194. [CrossRef] 
16. Chang, X.; Wang, T.; Gong, J. $\mathrm{CO}_{2}$ photo-reduction: Insights into $\mathrm{CO}_{2}$ activation and reaction on surfaces of photocatalysts. Energy Environ. Sci. 2016, 9, 2177-2196. [CrossRef]

17. Bae, D.; Seger, B.; Hansen, O.; Vesborg, P.C.K.; Chorkendorff, I. Durability testing of photoelectrochemical hydrogen production under day/night light cycled conditions. ChemElectroChem 2019, 6, 106-109. [CrossRef]

18. Zeng, J.; Li, Z.; Peng, H.; Zheng, X. Core-shell Sm $\mathrm{S}_{3} @ \mathrm{ZnO}$ nano-heterostructure for the visible light driven photocatalytic performance. Colloids Surf. A 2019, 560, 244-251. [CrossRef]

19. Ullah, R.; Dutta, J. Photocatalytic degradation of organic dyes with manganese-doped ZnO nanoparticles. J. Hazard. Mater. 2008, 156, 194-200. [CrossRef]

20. Samadi, M.; Zirak, M.; Naseri, A.; Khorashadizade, E.; Moshfegh, A.Z. Recent progress on doped ZnO nanostructures for visible-light photocatalysis. Thin Solid Films 2016, 605, 2-19. [CrossRef]

21. Whang, T.-J.; Hsieh, M.-T.; Chen, H.-H. Visible-light photocatalytic degradation of methylene blue with laser-induced Ag/ZnO nanoparticles. Appl. Surf. Sci. 2012, 258, 2796-2801. [CrossRef]

22. Chauhan, A.; Rastogi, M.; Scheier, P.; Bowen, C.; Kumar, R.V.; Vaish, R. Janus nanostructures for heterogenous photocatalysis. Appl. Phys. Rev. 2018, 5, 041111. [CrossRef]

23. Wang, P.; Huang, B.; Dai, Y. Myung-Hwan Whangbo Plasmonic Photocatalyst: Harvesting Visible Light with Noble Metal Nanoparticles. Phys. Chem. Chem. Phys. 2012, 14, 9813-9825. [CrossRef] [PubMed]

24. Atabaev, T.S.; Molkenova, A. Upconversion optical nanomaterials applied for photocatalysis and photovoltaics: Recent advances and perspectives. Front. Mater. Sci. 2019, 13, 335-341. [CrossRef]

25. Chen, C.; Liu, J.; Liu, P.; Yu, B. Investigation of Photocatalytic Degradation of Methyl Orange by Using Nano-Sized ZnO Catalysts. Adv. Chem. Eng. Sci. 2011, 1, 9-14. [CrossRef]

26. Sirelkhatim, A.; Mahmud, S.; Seeni, A.; Kaus, N.H.M.; Ann, L.C.; Bakhori, S.K.M.; Hasan, H.; Mohamad, D. Review on Zinc Oxide Nanoparticles: Antibacterial Activity and Toxicity Mechanism. Nano Micro Lett. 2015, 7, 219-242. [CrossRef]

27. Krstulović, N.; Umek, P.; Salamon, K.; Capan, I. Synthesis of Al-doped ZnO nanoparticles by laser ablation of $\mathrm{ZnO}: \mathrm{Al}_{2} \mathrm{O}_{3}$ target in water. Mater. Res. Express 2017, 4, 105003. [CrossRef]

28. Mintcheva, N.; Aljulaih, A.A.; Wunderlich, W.; Kulinich, S.A.; Iwamori, S. Laser-Ablated ZnO Nanoparticles and Their Photocatalytic Activity Toward Organic Pollutants. Materials 2018, 11, 1127. [CrossRef]

29. Honda, M.; Goto, T.; Owashi, T.; Rozhin, A.G.; Yamaguchi, S.; Itoc, T.; Kulinich, S.A. ZnO nanorods prepared via ablation of $\mathrm{Zn}$ with millisecond laser in liquid media. Phys. Chem. Chem. Phys. 2016, 18, 23628. [CrossRef]

30. Krstulović, N.; Salamon, K.; Budimlija, O.; Kovač, J.; Dasović, J.; Umek, P.; Capan, I. Parameters optimization for synthesis of Al-doped ZnO nanoparticles by laser ablation in water. Appl. Surf. Sci. 2018, 440, 916-925. [CrossRef]

31. Zhang, D.; Liu, J.; Li, P.; Tian, Z.; Liang, C. Recent Advances in Surfactant-Free, Surface Charged and Defect-Rich Catalysts Developed by Laser Ablation and Processing in Liquids. ChemNanoMat 2017, 3, 512-533. [CrossRef]

32. Jang, Y.J.; Simer, C.; Ohm, T. Comparison of zinc oxide nanoparticles and its nano-crystalline particles on the photocatalytic degradation of Methylene Blue. Mater. Res. Bull. 2006, 41, 67-77. [CrossRef]

33. Rahman, Q.I.; Ahmad, M.; Misra, S.K.; Lohani, M. Effective photocatalytic degradation of Rhodamine B dye by ZnO nanoparticles. Mater. Lett. 2013, 91, 170-174. [CrossRef]

34. Moulder, J.F.; Stickle, W.F.; Sobol, P.E.; Bomben, K.D. Handbook of X-Ray Photoelectron Spectroscopy; Physical Electronics Inc.: Eden Prairie, MN, USA, 1995.

35. Krstulović, N.; Milošević, S. Drilling enhancement by nanosecond-nanosecond collinear dual-pulse laser ablation of titanium in vacuum. Appl. Surf. Sci. 2010, 256, 4142-4148. [CrossRef]

36. Tseng, C.-A.; Lin, J.-C.; Weng, W.-H.; Lin, C.-C. Photoelectron spectroscopy and optical properties of Al-doped $\mathrm{ZnO}$ films prepared by sputtering with radio frequency power applied to Al target. Jpn. J. Appl. Phys. 2013, 52, 025801. [CrossRef]

37. Plodinec, M.; Grčić, I.; Willinger, M.G.; Hammud, A.; Huang, X.; Panžić, I.; Gajović, A. Black TiO 2 nanotube array decorated with Ag nanoparticles for enhanced visible-light photocatalytic oxidation of salycilic acid. J. Alloys Compd. 2019, 776, 883-896. [CrossRef]

38. Čižmar, T.; Panžić, T.; Salamon, K.; Grčić, I.; Radetić, L.; Marčec, J.; Gajović, A. Low-Cost synthesis of $\mathrm{Cu}$-Modified Immobilized Nanoporous $\mathrm{TiO}_{2}$ for Photocatalytic Degradation of $1 \mathrm{H}-$ Benzotriazole. Catalysts 2020, 10, 19. [CrossRef] 
39. Wu, C.-H.; Chern, J.-M. Kinetics of Photocatalytic Decomposition of Methylene Blue. Ind. Eng. Chem. Res. 2006, 45, 6450-6457. [CrossRef]

40. Sakthivel, S.; Neppolian, B.; Shankar, M.V.; Arabindoo, B.; Palanichamy, M.; Murugesan, V. Solar photocatalytic degradation of azo dye: Comparison of photocatalytic efficiency of $\mathrm{ZnO}$ and $\mathrm{TiO}_{2}$. Sol. Energy Mater. Sol. Cells. 2003, 77, 65-82. [CrossRef]

41. Kumar, M.; Sharma, S.; Kumar, D. Removal of methylene blue and rhodamine B from water by zirconium oxide/graphene. Water Sci. 2016, 30, 51-60.

42. Balcha, A.; Yadav, P.O.; Dey, T. Photocatalytic degradation of methylene blue dye by zinc oxide nanoparticles obtained from precipitation and sol-gel methods. Environ. Sci. Pollut. Res. Int. 2016, 23, 25485-25493. [CrossRef]

43. Abdellah, M.H.; Nosier, S.A.; El-Shazly, A.H.; Mubarak, A.A. Photocatalytic decolorization of methylene blue using $\mathrm{TiO}_{2} / \mathrm{UV}$ system enhanced by air sparkling. Alex. Eng. J. 2018, 57, 3727-3735. [CrossRef]

(C) 2020 by the authors. Licensee MDPI, Basel, Switzerland. This article is an open access article distributed under the terms and conditions of the Creative Commons Attribution (CC BY) license (http://creativecommons.org/licenses/by/4.0/). 